\title{
Morphological Markedness in an OT-Grammar: zeros and syncretism*
}

\author{
Katya Pertsova \\ University of North Carolina, Chapel Hill
}

\section{Introduction}

This paper explores the role of morphological markedness constraints in an OT framework with interleaving of phonological and morphological constraints. Morphological markedness constraints are constraints against the realization of marked combinations of features. For example, a constraint like * [+GROUP + RESTRICTED $(*$ DUAL) would penalize any output with a single morpheme realizing features [+group +restricted]. Similar types of constraints are proposed in Calabrese (2011), where they are called "marking statements". However, Calabrese assumes that these constraints are absolute (if active) and that they operate during lexical insertion before phonology happens. Incorporating morphological markedness constraints into an OT grammar in which phonology and morphology are interleaved (possibly, in a serial manner) allows us to account for cases in which there is a tradeoff between phonological and morphological considerations favoring or banning zero morphology. Russian genitive plural (Gen-Pl) allomorphy is an example of such a case discussed in this paper. Additionally, morphological markedness constraints provide a way of capturing certain types of syncretisms through constraint interaction. These are syncretisms in which a morphologically marked cell in a paradigm under certain conditions is realized by an exponent which typically occurs in other less marked contexts (such cases are described as Impoverishment on alternative accounts). Finally, morphological markedness constraints can also be thought of as restricting over time the range of morphological contrasts that are made in a language.

The paper is organized as follows. First I present some background assumptions of an OT-model that handles both lexical insertion and phonological computation. Then I present a portion of the analysis of Russian Gen-Pl allomorphy demonstrating the interactions between phonological and morphological markedness. Finally, I use morphological markedness to analyze an example of Impoverishment in OT.

\section{Background}

2.1 Realizational model of morphology-phonology interleaving The idea that morphology and phonology are fully interleaved within a single competition-based component of grammar is explored in detail in Wolf (2008). Wolf's motivation was to provide a unified framework which is able to account for examples of phonology "trumping" morphology. Such examples include phonologically-conditioned mobile affixation (Kim, 2010), gender discord in French (Teeple, 2008), cases of phonologically conditioned suppletive allomorphy, and insertion of dummy morphemes for phonological reasons (Hale, 1973). Wolf proposes a serial version of OT with what he calles "Optimal Interleaving" of regular phonological constraints with morphological faithfulness-type constraints on the realization of morpho-syntactic features. Unlike in standard OT, the input to the grammar consists of syntactic trees which contain abstract feature-nodes, an assumption shared by other realizational or top-down theories of morphology (for similar assumptions in OT see Walker \& Feng (2004); Teeple (2008)). The lexicon provides a vocabulary of phonological URs for different morphemes paired with their grammatical and/or semantic features (e.g., /z/:[plural]). The output consists of chains of representations linked by correspondence relations of at least two different kinds: the syntactic feature nodes are linked with lexical entries by what I will call SM-correspondence (syntaxmorphology correspondence) and the phonological URs of lexical entries are linked with the phonetic surface

\footnotetext{
* I would like to thank Jennifer Smith, Elliott Moreton, and Aron Hirsch for their input and discussion, and Adam Albright for comments on earlier versions of this project. All oversights and mistakes are my own.
} 
forms by phonological IO-correspondence as illustrated in figure 1 below. The output chain in this example can be represented as: $(\sqrt{ }$ sock + PLURAL $)-(/ \mathrm{sak} /+/ \mathrm{z} /)-([\mathrm{saks}])$.

Figure 1: Derivation of the English word "socks"

\begin{tabular}{ll} 
LEXICON & \\
\hline morphemes: & $/$ sak $/: \sqrt{ }$ sock \\
& /z/ $:$ plural
\end{tabular}

SM-CORRESPONDENCE

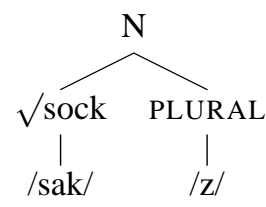

$\uparrow$ IO-CORRESPONDENCE [saks]

In this model, lexical items compete to be inserted into the syntactic representation via morphological faithfulness constraints such as $\mathrm{M}-\operatorname{DEP}(\mathrm{F})$ and $\mathrm{M}-\mathrm{MAX}(\mathrm{F})$. M-DEP(F) is violated when a morphological feature $F$ is present in the lexical item used in the output but not present in the syntactic input; M$\operatorname{MAX}(\mathrm{F})$ is violated when a morphological feature $F$ is present in the syntactic input, but is not part of the corresponding lexical item in the output. These constraints can have the same effect on lexical insertion as the Subset Principle of Distributive Morphology (Halle \& Marantz, 1993) or the Elsewhere Principle in Stump's Realizational theory (Stump, 2001): namely, a lexical entry whose features constitute the largest possible subset of the morpho-syntactic features wins the competition. For further discussion of this and the difference between this approach and the Subset Principle see Wolf (2008). In Wolf's version of serial OT, morphemes are spelled out one at a time. Crucially, we can assume that one of the competitors at each step in the process of lexical insertion is a form that does not differ in any way from its derivational base: it has no morphemes inserted and, thus, realizes no new features. On the surface this looks like zero-affixation. Such non-realization of a morpho-semantic node may be optimal if all forms with overt realizations violate some higher ranked constraints in the grammar, including phonological constraints. This fact can be used to model cases in which morphemes are omitted for phonological reasons (e.g., due to identical adjacent segments or morphs), but also, as I show in this paper, cases of morpheme omission due to morphological markedness.

2.2 Morphological markedness Several different types of markedness have been distinguished by linguists (Zwicky, 1978; Haspelmath, 2006). The notion of markedness that I am concerned with here is conceptual or semantic at its roots. Calabrese (2011) describes it like this: "Categories that are more basic, obvious, and easily connected to our everyday experience can be expected to serve as a conceptual background." The background categories are less marked. Conceptual markedness often (although not always) goes hand in hand with material markedness: unmarked categories have phonologically simpler exponents, and often are zero-marked (Croft, 2003; Brunner, 2010). Typological implicational markedness (familiar from the Prague School) can also be a sign of conceptual markedness. This is reflected in the fact that many explanations of typological markedness are rooted in specific assumptions about the (presumably universal) organization of the morpho-semantic features. A common example are number categories. For instance, Greenberg's universal stating that languages that mark dual also mark plural, can be derived from the fact that dual is a sub-category of plural on many analyses (e.g., in Silverstein (1976) both dual and plural are [+group] categories, but dual has an additional feature [+restricted]).

In addition, there are general cross-linguistic tendencies for marked structures and oppositions to be reduced or simplified over time. It is because of this tendency that markedness has featured prominently in theoretical linguistics, and in accounts of zero-realization and syncretism in particular. For instance, in the framework of Distributed Morphology (DM), lexical entries can undergo deletion of marked feature values (and possibly subsequent insertion of the unmarked values), called "Impoverishment" (Bonet, 1991; Noyer, 1998). Impoverishment results in syncretism when deletion of some feature(s) from a lexical entry makes its insertion into a particular environment no longer possible, and another "default" entry is inserted instead. Calabrese (2011) extends this process of deletion of marked structures to the morpho-syntactic level in addition to the lexical level. He proposes that morphological markedness can trigger "obliteration," deletion of a marked node in syntax leading to zero exponence (also see Arregi \& Nevins (2006)). Calabrese's account is intended to explain why the distribution of zeros often mirrors the distribution of syncretic morphemes in related paradigms. 
Like Calabrese, I assume existence of morphological markedness constraints that form a markedness hierarchy. A morphological markedness constraint bans realization of some particular combination of syntactic features (possibly in a particular context). The family of such constraints forms a universal markedness hierarchy. Constraints penalizing realization of more marked feature sets are ranked higher in the hierarchy than constraints penalizing realization of less marked feature sets. For example, a constraint like *1 PERSON PLURAL would be ranked above *1 PERSON SINGULAR and above *PLURAL. This makes a prediction that if some process is triggered by a particular markedness constraint, it should also be generally triggered by all of the markedness constraints ranked higher in the hierarchy. For instance, if we say that 1 st person singular is not overtly realized due to the fact that *1PERSON is ranked above M-MAX(1PERSON), then we expect that 1 st person plural will also not be overtly realized. The predictiveness of this theory is maintained only if we assume that lexically specified zeros (which are hard to tell apart from morpheme omission) are restricted to a small set of lexical items. Like Calabrese I adopt a Jakobsonian assumption that this restricted set corresponds to the fully unmarked morphemes. So, morphological zeros can occur in the unmarked environments as zero-exponents or in the sufficiently marked environments due to morpheme omission. However, of course some instances of morpheme omission will arise for phonological reasons. (Thus, all zeros unexplained on morphological grounds, should be phonologically motivated.)

2.3 Predictions of the Morphological Markedness constraints When morphological markedness constraints are outranked by the corresponding morphological faithfulness constraints, their effects are invisible. When the ranking is the opposite - there are two types of possible scenarios:

a. Emerging zeros: complete or partial markedness reversals This is a situation in which the morphologically marked morpheme appears to be not realized, leading to zeros in marked environments. This is sometimes referred to as a markedness reversal, because the typical state of affairs is for zeros to occur in unmarked contexts. A partial markedness reversal occurs when zero-realization of the marked morpheme may be sometimes blocked by higher ranked constraints.

b. Syncretism: substitution of a less marked morpheme: This situation arises when a language possesses lexical items that allow (under a specific constraint ranking) realization of a partial set of features from those that are banned by a morphological markedness constraint.

A frequently cited example of a markedness reversal is the regular verbal inflection in the English present tense: $-s$ marks the most semantically unmarked cell in the paradigm (3p.sg.), while all the other cells are zero-marked. This could be analyzed by the high ranking of *PARTICIPANT (1/2 PERSON) 1 and *PLURAL. An alternative is of course to posit a lexical entry $-\varnothing$ which is completely underspecified for person and number, and thus occurs everywhere where -/z/ does not. However, a theory which assumes that any lexical entry can correspond to a zero exponent, makes no predictions for where we are more likely to observe zeros. Other examples of possibly morphological zeros can be found in the clitic paradigms in some Italian dialects (Manzini \& Savoia, 2005; Calabrese, 2011) where no overt clitics exist for the most marked combinations of person and number, and in Muisca (an extinct language of Colombia), where the unmarked non-past tenses on the verbs are overt, while the past tense is Ø (López García, 1995).

The Russian genitive plural allomorphy discussed in the next section presents an example of another markedness reversal in which the marked combination of features, [Gen.Pl.], is by default not overtly realized unless it leads to violations of certain higher ranked constraints. Among these constraints is a paradigmatic contrast constraint that punishes forms homophonous with the citation form (Nom-Sg), but also some phonological constraints discussed shortly. Thus, this case presents an example of phonology trumping morphology, and is, therefore, problematic for theories in which morphology strictly precedes phonology. Cases of this sort provide support for placing morphological markedness constraints in the same grammatical component as phonological constraints.

The second prediction of morphological markedness constraints in (b) above states that they can lead to syncretism. This is because another way of avoiding a violation of a morphological markedness constraint is to realize a subset of the marked features, instead of not realizing them at all. When this is possible

1 The features participant is often used to refer to the participants in the speech discourse, that is speakers (1st person) and listeners (2nd person). 
(due to availability of specific lexical entries), syncretism results. Thus, we can model Impoverishment with constraint interaction, which will be shown in the last section of this paper.

\section{Genitive plural allomorphy in Russian}

Russian Gen-Pl allomorphy is presented here as an example of a partial markedness reversal (see 1(a)) due to an interaction of phonological and morphological constraints within an OT-style grammar.

3.1 Background Russian nouns are divided into three inflectional classes based on the phonological form of the Nom-Sg and on grammatical gender. However, the declensional class differences are neutralized in the plural with all nouns having the same set of inflections across each case except in the Gen-Pl. In the Gen-Pl there are three allomorphs, which (at least synchronically) cannot be derived from a single underlying representation. They are:

(2) Genitive Plural Allomorph 2
a. $\quad-$ /ov/ (realized as [of] when stressed or [əf] when unstressed)
Example: "table" [stol-Ø] (nom.sg.) - [stal-óf] (gen.pl.)
b. - -/ej/ (realized as [ej] when stressed or [ij] when unstressed)
Example: "horse" [kón $\left.{ }^{\mathrm{j}}-\varnothing\right]$ (nom.sg) - [kan-éj] (gen.pl)
c. $-/ \varnothing /$
Example: "book" [kníg-a] (nom.sg) - [kník-Ø] (gen.pl)

While this allomorphy is historically related to the singular inflectional classes, this connection cannot be maintained synchronically. Nouns of the same inflectional class can have different allomorphs in the Gen$\mathrm{Pl}$ (e.g., neuter nouns ending in -o mostly appear with the zero Gen-Pl as in lits-o - lits- $\emptyset$ "face," but they can also sometimes select -/ej/ as in $m o r^{j}-o-m o r^{j}-e j$ "sea," or the allomorph -/ov/ as in plat jj-o - plat j$o v$ "dress"). Nevertheless, there are correlations between inflectional class and Gen-Pl allomorphs in so far as there is a correlation between the forms of Gen-Pl and the Nom-Sg noticed by Jakobson (1957). This correlation can be formulated as the following generalization (which has exceptions):

(3) If the Nom-Sg suffix is null, the Gen-Pl suffix is overt (-/ej/ or -/ov/ depending on the palatalization of the preceding consonant); if the Nom-Sg suffix is overt (-a or -o), the Gen-Pl suffix is null.

This generalization is illustrated by the following examples.

$$
\begin{aligned}
& \text { Nom-Sg - Gen-Pl dependency } \\
& \text { a. [rólj-Ø]-[ral -éj] "role" } \\
& \text { [stól-Ø] - [stal-óf] "table" } \\
& \text { b. [nedéli-a] - [nedéli- } \emptyset] \text { "week" } \\
& \text { [v } \left.{ }^{\mathrm{j}} \text { in-ó] - [ v }{ }^{\mathrm{j} i ́ n}-\emptyset\right] \text { "wine” }
\end{aligned}
$$

This interparadigmatic relationship between two seemingly arbitrary forms appears highly unusual and contradicts phonological theories in which different surface forms can only influence each other through OO-Correspondence if they are featurally minimally different (Kager, 1999) or if they constitute different intermediate steps in a cyclic derivation as in Lexical Phonology. Taking these assumptions as a starting point, Bailyn \& Nevins (2008) provide an analysis of the Russian Gen-Pl allomorphy which tries to avoid positing a direct correspondence between the Nom-Sg and the Gen-Pl. They propose that the conditioning factors are purely phonological, namely stem-final segments. In order to make this analysis work, Bailyn and Nevins have to assume that the Nom-Sg suffixes $-a$ and $-o$ are actually theme-vowels and, therefore, are part of the stem. These vowels surface only in the Nom-Sg because in all other forms they appear before a vowel and are, therefore, deleted by a regular phonological rule. The Gen-Pl allomorphs are then conditioned as follows: $-/ \varnothing /$ (or more specifically, a yer vowe ${ }^{3}$ ) is selected when the theme vowel is overt (before it

2 Vowel and consonant alternations seen in these and other examples are due to the processes of vowel reduction and final consonant devoicing. For a discussion of these alternations see Jones \& Ward (1969).

3 Yers are high lax vowels that were lost in most unstressed environments, but still surface as mid vowels in Modern Russian in some words to break up complex codas or sonority violating consonant clusters (Yearley, 1995; Gouskova, 
is deleted), and -/ov/ and -/ej/ are selected when the theme-vowel is null with -/ej/ following palatalized consonants, and -/ov/ following all other consonants. The reason why theme vowels are not realized in the Gen-Pl which is zero-marked is because the zero is really a yer which first triggers the deletion of the themevowel and then deletes itself. Unfortunately, this analysis is highly opaque relying on several distinctions that are never visible on the surface except for the distinctions in the Nom-Sg forms. For this reason, it is not clear that this analysis has any advantage over positing a direct dependency between the Nom-Sg and the Gen-Pl.

3.2 A markedness approach As I show elsewhere, the generalization in (3) is very reliable, but it is not without exceptions (Pertsova, 2004) These exceptions together with a pattern of allomorph distribution in the pluralia tantum nouns (nouns without singular forms), point to a different account of the facts. Due to space limitations, in this paper I will not be able to describe all of the subgeneralizations in the of GenPl allomorphy. I will focus just on demonstrating a few examples of tradeoffs involving morphological markedness constraints.

First, I assume that the $-/ \varnothing /$ in the Gen-Pl is in fact an absence of a morpheme due to a morphological markedness constraint punishing outputs that contain a morpheme marked for both plurality and genitive case. In adopting this markedness approach, I follow Jakobson who suggested in his original paper on the relationship between the Nom-Sg and Gen-Pl in Russian that the Gen-Pl is doubly marked for quantity: plural is an obvious marker of quantity, and so is Genitive to some extent. According to Jakobson, Genitive frequently signals some sort of restriction on the referent; it is also often used with a partitive meaning which is related to quantity. Taking this idea seriously, I propose that the reason the Gen-Pl is often zero-marked in Russian is because of high ranking of a markedness constraint against the combination of features [Gen] and [Pl] within a single morpheme.

*GEN.PL.: incur a violation if the output chain contains a lexical item specified for the features [Gen. $\mathrm{Pl}$.]

So, by default the Gen-Pl is not overtly realized unless this leads to problems elsewhere. In particular, if this leads to homophony with the Nom-Sg, the Gen-Pl is realized overtly. here are several pieces of evidence supporting the homophony-avoidance hypothesis. The one that I discuss here has to do with nouns whose singular and plural stems differ from each other due to some derivational morphemes. These nouns can have $\varnothing$ in both the Nom-Sg and the Gen-Pl because the two wordforms are no longer homophonous (see examples below).

(6) Nouns with different singular and plural stems:

\begin{tabular}{lll} 
nom.sg. & gen.pl & gloss \\
\hline grazdan-in- $\varnothing$ & grazdan- $^{\text {da }}$ & citizen \\
dvor $^{\mathrm{j}}$ an-in- $\varnothing$ & dvor $^{\mathrm{j}}$ an- $\varnothing$ & aristrocrat \\
kot $^{\mathrm{j}}$-on-ok- $\varnothing$ & kot $^{\mathrm{j}}$-at- $\varnothing$ & kitten \\
ut $^{\mathrm{j}}$-on-ok- $\varnothing$ & ut $^{\mathrm{j}}$-at- $\varnothing$ & duckling
\end{tabular}

A prominent subclass of such nouns are certain nationality names such as tatar-in "Tatar," bolgar-in "Bulgarian," moldavan-in "Moldovan," mogikan-in "Mohican" with the singulative suffix -in in their singular stems. All such nationality names have $\varnothing$ in the Gen-Pl in contrast to other nationality names that do not

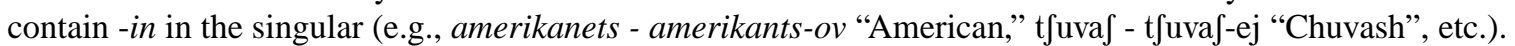
In this respect it is interesting to consider the behavior of a noun gruzin "Georgian." While this noun ends in a string -in, this string is not a singulative suffix but is part of the stem as it appears in all plural forms (cf. gruzin-i "Georgians, nom.pl."). There is a strong analogical pull from other nationality names ending in -in that may lead speakers to choose the Gen-Pl form gruzin- $\varnothing$. However, such a choice would create homophony with the Nom-Sg and is expected to be avoided. In fact, speakers feel uncertain about the Gen-Pl of this noun, and both forms, gruzin-ov and gruzin, are equally attested. Based on a Google search, restricting the language to Russian and the phrase to "about Georgians" the number of hits for pro gruzin was 91,000 $(56 \%)$ and for "pro gruzin-ov" - 72,900 (44\%). Compare this with the distribution of "about Tatars": pro tatar - 159,000 (97\%) vs. pro tatar-ov - 6,140 (3\%). Many of the hits for the phrase "about Georgians" were metalinguistic discussions about what the "correct" form of this word is. The uncertainty that speakers experience 
with "Georgian" supports the idea that they are sensitive to the homophony violation. For additional evidence supporting homophony avoidance see Pertsova (2014).

To sum up what I have argued so far, the complementary distribution of $\emptyset_{\mathrm{s}}$ in the Nom-Sg and the Gen-Pl is due to a tradeoff between two factors: markedness of the Gen-Pl and homophony avoidance with the citation form, the Nom-Sg 4 The latter factor can be formulated as the following constraint (for other proposals in OT documenting antihomophony effects see Crosswhite (1999); Rebrus \& Törkenczy (2005); Kenstowicz (2005); Ito \& Mester (2004); Lubowicz (2007)):

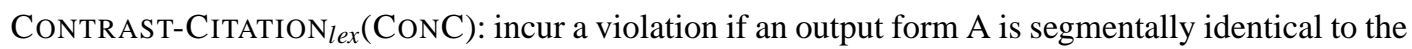
citation form of the lexeme that A belongs to.

We can now construct a simple account of the nearly complementary distribution of $\varnothing$ in the Nom-Sg and the Gen-Pl. First, the preferred non-realization of the Gen-Pl morpheme is captured by the ranking

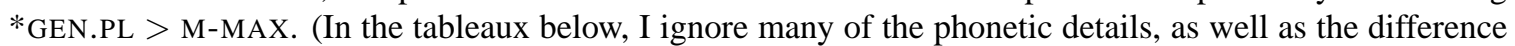
between the two overt Gen-Pl allomorphs - the choice between them depends on the palatalization of the stem-final consonants which can be modeled by an AGREE[BACK] constraint requiring that the adjacent consonant vowel sequences agree for the feature [back]. I will only consider candidates that satisfy this AGREE constraint.)

\begin{tabular}{|l||c|c|}
\hline /vin/ + gen.pl. (nom.sg. = vino) & *GEN.PL. & M-MAX \\
\hline \hline a. vin- $\varnothing$ & & $*$ \\
\hline b. $\quad \operatorname{vin}_{\text {-Ov }}$ Gen.Pl. & $* !$ & \\
\hline
\end{tabular}

This default preference is blocked by the anti-homophony constraint:

\begin{tabular}{|l||c|c|c|}
\hline$/$ tron/ + gen.pl. (nom.sg. $=$ tron) & CONC & $*$ GEN.PL. & M-MAX \\
\hline \hline a. tron- $\varnothing$ & $* !$ & & $*$ \\
\hline b. tron-ov $_{\text {Gen.Pl. }}$ & & $*$ & \\
\hline
\end{tabular}

In addition, the default preference for non-realization can be overriden by a phonotactic constraint on coda clusters ending in a glide:

(10) $\mathrm{CJ}]_{\sigma}$ : incur a violation for every instance of a consonant followed by a glide in a coda final position

The constraint above is inviolable in Russian (e.g., there are no words like $* \operatorname{sinj}$ or $*_{\sin }^{j} j$ ). However, there are stems that end in a sequence $\mathrm{Cj}$. When these stems are suffixed, the cluster with the glide is syllabified as the onset of the following syllable (since all nominal inflectional suffixes in Russian are vowel-initial): e.g., /pla. $t^{j} j-o /$ "dress." If a word of this type did not overtly realize the Gen-Pl morpheme, then the offending cluster would become word-final. There is no general repair for such clusters in Russian. However, a lexically specific group of words containing underlying yer-vowels is able to repair bad clusters by realizing the yers (for a recent OT-account of yers see Gouskova (2012)). Crucially, there is no way to predict which lexical items contain a yer and which do not. Examples below show the Gen-Pl forms of yer vs. non-yer nouns with $\mathrm{Cj}$ clusters:

(11) Words with $\mathrm{Cj}$ clusters either realize a yer (underlined), or select an overt Gen-Pl allomorph:

\begin{tabular}{|c|c|c|}
\hline nom.pl. & gen.pl & gloss \\
\hline$\left[a z \mathrm{r}^{\mathrm{j}} \mathrm{é}^{\mathrm{j}} \mathrm{j}-\partial\right]$ & [azวr $\left.\mathrm{r}^{\mathrm{j}} \mathrm{é}^{\mathrm{j}}{ }^{\mathrm{Ij}}\right]$ & necklace \\
\hline [súd $\mathrm{d}_{\mathrm{j}}^{\mathrm{j}-\partial]}$ & {$\left[\mathrm{súd}^{\mathrm{j}} \mathrm{Ij}\right]$} & judge \\
\hline [plátjj-ə] & [plát $\left.{ }^{\mathrm{j}} \mathrm{j}-\mathrm{j}\right]$ & dress \\
\hline$\left[\mathrm{kr} \dot{\mathrm{i}} \mathrm{l}^{\mathrm{j}}-\mathrm{j}-\partial\right]$ & {$\left[\mathrm{krí}^{\mathrm{j}} \mathrm{j}_{-j} \mathrm{j}-\partial \mathrm{f}\right]$} & wing \\
\hline
\end{tabular}

The above data shows that the overtness of the Gen-Pl can also be affected by phonology: the last two nouns

4 So, the Nom-Sg must be stored in the speakers' lexicon as an inflectional base which can be referenced during the derivation of other forms. 
in (11) should have a zero Gen-Pl (homophony is not an issue for them because they either have an overt Nom-Sg suffix or a derivational suffix $-\mathrm{j}$ in the plural stem), but instead they choose an overt allomorph to avoid a violation of an inviolable phonotactic constraint:

\begin{tabular}{|c|c|c|c|c|c|}
\hline$/$ plat $^{\mathrm{j}} \mathrm{j} /$ + gen.pl. (nom.sg. $=$ plat $\left.^{\mathrm{j}} \mathrm{jo}\right)$ & $\mathrm{CJ}]_{\sigma}$ & $\operatorname{DEP}(\mathrm{V})$ & $\mathrm{CONC}$ & *GEN.PL. & M-MAX \\
\hline a. $\quad$ plat $\mathrm{j}_{\mathrm{j}-\varnothing}$ & $* !$ & & & & * \\
\hline b. $\quad$ pla. $\mathrm{t}^{\mathrm{j}} \mathrm{ej}$ & & $* !$ & & & $*$ \\
\hline c. pla. $^{\mathrm{j}} \mathrm{j}-\mathrm{ov}_{G e n . P l}$. & & & & $*$ & \\
\hline
\end{tabular}

Finally, let's consider the question of why the analysis above in which a morphological markedness constraint interacts with other constraints in the grammar should be preferred to an analysis in which one of the Gen-Pl allomorphs is specified as $\varnothing$ in the lexicon. On this alternative analysis, we would have to find some other

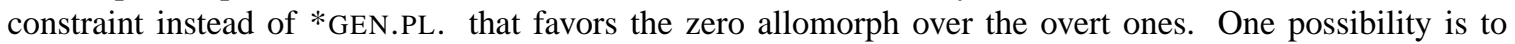
assume something like ECONOMY, disliking all surface segments and, so, favoring shorter allomorphs over the longer ones. However, this will not be sufficient to account for the difference between feminine nouns like nede $l^{\prime}-a$ "week" which have $\varnothing$ in the Gen-Pl (nede $l^{j}-\varnothing$ ), and phonologically similar pluralia-tantum nouns like $k a c h e l_{-}-i$ "swings" which select the overt allomorph -/ej/ (kachel $\left.{ }^{j}-e j\right)$. The ECONOMY constraint would favor zero for both of these nouns, and if some phonological constraint outranked ECONOMY (e.g., a ban on word-final palatalized consonants), then both of these nouns should appear with -/ej/. Since the only difference between the two nouns above is that one of them is a pluralia-tantum noun, the other alternative would be to assume that $\varnothing$ is actually specified for a particular declension class or non-masculine gender (which would restrict it to nouns ending in $-a$ and $-o$ ). Yet, this would not be a desirable result as we have already seen that $\varnothing$ also sometimes occurs with nouns that do not end in $-a$ and - $o$ (see examples in (6). It also occurs with many pluralia-tantum nouns (e.g., /bus-i/ - /bus- $\emptyset /$ "beads") or nouns that are used more frequently in the plural (e.g.. /glaz- $\varnothing /$ "eye nom.sg/gen.pl." 5 . Besides, subcategorizing Gen-Pl allomorphs for a specific inflectional class would go against the fact I mentioned earlier that inflectional class distinctions are neutralized in the rest of the plural paradigm.

Instead, I propose that nouns like nedel $\dot{j}_{-} a$ "week" not only violate the constraint *GEN.PL., but also violate a higher ranked morphological markedness constraint *GEN.PL./[-MASC] prohibiting realizations of Gen-Pl when combined with stems of more marked genders: feminine and neuter. Masculine nouns and pluralia-tantum nouns (which lack gender) are not affected by this constraint. This explains the greater resistance of feminine and neuter nouns to realize Gen-Pl overtly 6

Due to positional markedness of word-final palatalized consonants, the overt allomorph -/ej/ will be preferred for nouns whose stems end in a palatalized consonant. The relevant constraint, motivated by perceptual disadvantage of the palatalization contrast in the final position (Kochetov, 2002), is this:

$$
* \mathrm{C}^{\mathrm{J}} \# \text { : assign a violation for an output that contains a [-back] consonant at the end of a word. }
$$

The difference between the two nouns discussed above is modeled as follows:

\begin{tabular}{|c|c|c|c|c|}
\hline /katféj $\mathrm{j}$ + gen.pl. (plural only) & $*_{\text {GEN.PL/[-MASC }]}$ & $* C^{\mathrm{J}} \#$ & $*_{\text {GEN.PL }}$ & M-MAX \\
\hline a. $\quad$ katféli- $\varnothing$ & & $* !$ & & * \\
\hline b. $\because$ katfél $^{\mathrm{j}}-\mathrm{ej}_{G e n . P l}$ & & & * & \\
\hline
\end{tabular}

5 More specifically, zeros are most likely to occur with such nouns if their stems are stressed and do not end in a palatalized consonant. The fact that Øoccur in pluralia-tantum nouns for which other phonological factors do not play a role, is another evidence for the fact that Øis the default realization of the Gen-Pl.

6 This resistance is evident from two facts: (1) as alluded to above, pluralia tantum nouns ending with a palatalized consonant prefer an overt Gen-Pl to avoid word-final palatalization, while similar feminine and neuter nouns do not, (2) pluralia tantum nouns with stress on the suffix prefer an overt Gen-Pl to avoid shifting stress to the stem, while similar feminine and neuter nouns generally do not. For feminine and neuter nouns to select an overt allomorph both of the phonological factors must be met: the stem has to end in a palatalized consonant and the stress has to fall on the suffix in the plural (e.g., stez $\left.z^{j}-\dot{a}-s t e z^{j}-e ́ j\right)$. 


\begin{tabular}{|l||c:c|c|c|}
\hline /nedélj/fem + gen.pl. & $*_{\text {GEN.PL/[-MASC] }}$ & $* \mathrm{C}^{\mathrm{J}} \#$ & $*$ GEN.PL. & M-MAX \\
\hline \hline a. nedél ${ }^{\mathrm{j}}-\mathrm{ej}_{\text {Gen.Pl. }}$ & $*$ & & $* !$ & $*$ \\
\hline b. nedélj- $\varnothing$ & & $*$ & & \\
\hline
\end{tabular}

The portions of the analysis presented here are sufficient to show that morphological markedness is one of the factors driving Gen-Pl allomorphy in Russian. The other factors include homophony avoidance and independently motivated phonological constraints. The interaction of all these factors within a single grammar gives rise to a pattern of allomorph distribution that would be hard, if not impossible, to capture in modular theories in which morphology precedes or follows phonology. Further support for morphological markedness constraints that apply in specific environments, like *GEN.PL/[-MASC], is presented in the next section.

\section{Impoverishment through constraint-interaction}

In this section, I use an example from Spanish to demonstrate how morphological markedness constraints can account for certain cases of syncretism. I will consider the case of Spanish pronominal clitics discussed in Halle \& Marantz (1994). In particular I will focus on the diachronic change during which 2nd person plural clitics in American Spanish dialects have taken on the forms of the 3p.pl. clitics (I will ignore the problem of spurious "se" also discussed in that paper). The table below gives a full paradigm of the clitics in the Latin American dialects of Spanish and in parenthesis the equivalent clitics in the source dialect, the Peninsular Spanish:

Pronominal clitics in Spanish (from Halle and Marantz 1994)

\begin{tabular}{|c|c|c|c|c|c|}
\hline & & \multicolumn{2}{|c|}{3 person } & 2 person & 1 person \\
\hline & & $\mathrm{m}$ & f & $\mathrm{m} / \mathrm{f}$ & $\mathrm{m} / \mathrm{f}$ \\
\hline \multirow[t]{2}{*}{ Acc } & $\mathrm{sg}$ & lo (1-o) & la (1-a) & te $(\mathrm{t}-\mathrm{e})$ & me (me) \\
\hline & $\mathrm{pl}$ & los (1-O-S) & las (1-a-s) & $\operatorname{los}(\mathrm{O}-\mathrm{S})$ & nos (n-o-s) \\
\hline \multirow[t]{2}{*}{ Dat } & $\mathrm{sg}$ & \multicolumn{2}{|c|}{ le (1-e) } & te $(\mathrm{t}-\mathrm{e})$ & me (me) \\
\hline & $\mathrm{pl}$ & \multicolumn{2}{|c|}{ les (l-e-s) } & les (o-s) & nos (n-o-s) \\
\hline \multirow[t]{2}{*}{ Reflexive } & $\mathrm{sg}$ & \multirow{2}{*}{\multicolumn{2}{|c|}{ se (s-e) }} & te $(\mathrm{t}-\mathrm{e})$ & me (me) \\
\hline & $\mathrm{pl}$ & & & se (o-s) & nos (n-o-s) \\
\hline
\end{tabular}

Notice that in the Latin American dialects, the second person plural clitics are systematically replaced by the corresponding 3rd person plural clitics, while in Peninsular Spanish the 2nd person plural clitic is os. The dashes present in the Peninsular Spanish clitics indicate their internal structure according to an analysis by Jim Harris that Halle and Marantz adopt. In particular, Harris assumes that the clitics are composed of three elements: a stem, a theme vowel, and a number marker. To account for the Latin American dialects, Halle and Marantz propose a Rule of Impoverishment that deletes the feature [2nd person] from the vocabulary item for the 2 person stem, $\varnothing$ :[2person]:

$$
[2 \text { nd person }] \rightarrow \varnothing / \text { governed by }[+\mathrm{Pl}]
$$

They also assume that the default stem for Acc and Dat is $l$-, so this stem becomes inserted into the "impoverished" morphological node after 2nd person feature is deleted from it. It is not clear, however, why the theme vowel in the dative 2p.pl. clitic also changes from 'o' to 'e.'

Below I present an account of the same facts using markedness constraints in OT. First, I assume that the reason why the infrequent and marked 2p.pl. forms were replaced by the $3 \mathrm{p} . \mathrm{pl}$. forms is that the third person lacks person features being the unmarked person. The assumed set of privative features is summarized below: 
Person, number, and gender features in Spanish

\begin{tabular}{ll}
3 person & {[]} \\
1 person & {$[+$ speaker $]$} \\
2 person & [+addressee] \\
\hline singular & {[]} \\
plural & {$[+$ pl. $]$} \\
\hline masculine & {[]} \\
feminine & {$[+$ fem. $]$}
\end{tabular}

The table below lists the lexical entries for the clitics. Notice that in my analysis, the clitics are not decomposed into the three components as proposed by Harris. I take the fact that the Latin American dialects replaced the 2p.pl. clitic os by the case-corresponding 3p.sg. clitics, rather than replacing just the stem-element, as evidence that the speakers of those dialects were not decomposing the clitics into multiple morphemes. The lexicon below represents a hypothesis about the initial state of the grammar before the 2p.pl. clitic os has been completely replaced. (For simplicity, I'll use the features [1p.] and [2p.] instead of [+speaker] and [+addressee]).

(19) Lexical entries for the clitics at an early stage in Latin American Spanish (same as in Peninsular Spanish):

\begin{tabular}{ll|ll} 
los & {$[+$ acc + pl. $]$} & lo & {$[+$ acc $]$} \\
las & {$[+$ acc + pl. + fem. } & la & {$[+$ acc + fem $]$} \\
les & {$[+$ dat + pl. $]$} & le & {$[+$ dat $]$} \\
os & {$[2$ p. + pl. $]$} & te & {$[2 p]$.} \\
nos & {$[1$ p. + pl. $]$} & me & {$[1 \mathrm{p}]$.} \\
se & {$[-$ acc $]$} & &
\end{tabular}

So, in Peninsular Spanish, the 3rd person clitics are underspecified for person, while the $1 / 2$ person clitics are underspecified for case and gender. The reason why se is specified as [-acc] is because it can also occur in Dative contexts under certain conditions (known as spurious "se") which I do not discuss here. Given this set of entries and assuming that $\mathrm{M}-\mathrm{MAX}(2 \mathrm{P})$ constraint is ranked higher than the morphological markedness constraint defined below, we can derive the Peninsular Spanish paradigm. The morphological markedness constraint captures the same intuition as the Impoverishment rule in (17)

$* 2 \mathrm{P} /+\mathrm{PL}$ : incur a violation for every instance of a lexical item in the output bearing the feature [2person] occurring in a syntactic environment containing (or dominated / governed by) the node with the feature $[+\mathrm{pl}]$.

The ranking below shows a scenario in which the $2 \mathrm{p}$. plural clitic os surfaces faithfully. It also demonstrates that when multiple clitics are compatible with the same morpho-syntactic environment, the clitic satisfying the largest number of features and containing no extra-features is chosen as a winner. M-MAX(2P) outranks $\operatorname{M-MAX}(\mathrm{ACC})$, accounting for the fact that it is more important to realize the person rather than the case feature in the 2 person in Peninsular Spanish. I make no specific assumptions about the syntactic structures, and so use the unstructured bundles of features in the input as an idealization.

Faithful realization of $o s$

\begin{tabular}{|c|c|c|c|c|c|}
\hline$[2 \mathrm{p} .+\mathrm{acc}+\mathrm{pl}]$ & M-DEP & $M-\operatorname{MAX}(2 P)$ & $* 2 \mathrm{P} /+\mathrm{PL}$ & M-MAX(ACC) & $\mathrm{M}-\mathrm{MAX}(\mathrm{PL})$ \\
\hline a. & & & $*$ & $*$ & 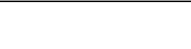 \\
\hline b. te: $[2 p]$. & & & $*$ & $*$ & $* !$ \\
\hline c. los: $[+\mathrm{acc}+\mathrm{pl}]$ & & $* !$ & & 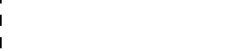 & 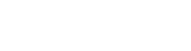 \\
\hline d. $\quad$ se: $[-\mathrm{acc}]$ & $* !$ & * & & * & $*$ \\
\hline
\end{tabular}

So, the clitic os wins in the $2 \mathrm{p}$. accusative plural context. But los will be chosen for the $3 \mathrm{p}$. accusative plural because $o s$ will violate M-DEP(2P). Now, suppose that the morphological markedness constraint, $* 2 \mathrm{P} /+\mathrm{PL}$, becomes promoted above M-MAX (2P). 
The retreat to the unmarked

\begin{tabular}{|c|c|c|c|c|c|}
\hline$[2 \mathrm{p} .+\mathrm{acc}+\mathrm{pl}]$ & $* 2 \mathrm{P} /+\mathrm{PL}$ & M-DEP & $M-M A X(2 P)$ & M-MAX(PL) & $\mathrm{M}-\mathrm{MAX}(\mathrm{ACC})$ \\
\hline a. $\operatorname{los}:[+\mathrm{acc}+\mathrm{pl}]$ & & & $*$ & & \\
\hline b. $\varnothing$ & & & $*$ & $* !$ & $*$ \\
\hline c. $\quad$ os: $[2 p .+p l]$ & $* !$ & & i & & * \\
\hline d. te: [2p.] & $* !$ & & 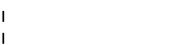 & $*$ & $*$ \\
\hline e. $\quad$ se: $[-a c c]$ & & $* !$ & $*$ & $*$ & $*$ \\
\hline
\end{tabular}

Under this constraint ranking, the 2nd person clitics are blocked by the morphological markedness constraint, and so the next most compatible lexical entry that does not contain the marked feature is chosen instead. Of course, after such a ranking becomes stable, os will never be realized and cease to exist as a separate clitic. That is, the speakers will not posit a separate lexical entry for 2 nd person plural. The only trace of its existence is the fact that the new Latin American paradigm makes case distinctions in the 2nd person plural, while no such distinctions are made in the 1st person or 2 nd person singular. This fact, of course, is the result of the syncretism with the 3person plural clitics. It is possible that the learners of Latin American dialects have restructured their grammar subsequent to this change to make los the default plural Accusative clitic, and les the default Dative plural clitic. In other words, highly ranked morphological markedness constraints can lead to collapse or reorganization of morphological oppositions through creation of syncretism. In the case described here, it is possible to reconstruct the historical development by comparing two closely related dialects. However, similar kinds of processes can happen within a single dialect as well when some morpheme can appear in unexpected places under a specific set of conditions (e.g., in presence of other marked morphemes).

Also, this approach (like Impoverishment) makes predictions about which patterns of syncretism due to markedness are more likely. For example, in the above case the 2p.pl. clitics were replaced by the 3p.pl., not the 3 p.sg. which is featurally the least marked form in the paradigm. In general, we expect that the most specific defaults would be used as substitutions for the marked morphemes, that is, the lexical entries that are not specified for the offending feature(s) but are still specified for the greatest number of features possible. When such lexical entries do not exist, non-realization (Ø-marking) emerges as the optimal choice.

\section{Conclusion}

In conclusion, including morphological markedness constraints in a grammar in which lexical spellout and phonology are interleaved allows one to account for two phenomena: appearance of zeros in morphologically marked contexts and the use of less marked morphemes in marked morpho-syntactic contexts. Crucially, such a grammar allows interactions between morphological and phonological markedness, predicting existence of the kinds of tradeoffs between morphology and phonology discussed in this paper with respect to the Russian Gen-Pl allomorphy. Another example is discussed in Artés (2014) (this volume), where in the Valencian dialect of Catalan, unexpected overt gender suffixes (- $a$ and $-o$ ) are inserted into a hypocoristic to satisfy the minimal word-requirement (words must be minimally bimoraic). So, the short name for Manel- $\varnothing$ is Nel-o (cf. Nel in Central Catalan) with an overt masculine allomorph -o instead of the expected default allomorph $\varnothing$. Catalan has a general-purpose epenthetic vowel, but $-o$ is better than an epenthetic vowel, because it satisfies a morphological requirement for realizing gender as well as fixes the phonological problem.

The model of grammar explored here, also predicts that syncretism should be able to interact with phonology. For example, one can imagine that "retreat to the unmarked" is blocked in certain environments where it creates phonological problems. Or phonological markedness itself can lead to syncretism. The use of "aren't" instead of "amn't" in tag questions (such as "I am right, aren't I?") is presented as one example of such a case. The difficulty with "amn't" is a phonological one. In the non-inverted form, speakers can avoid the problem by using "I' $m$ not" or the non-contracted version "I am not." However, in tag questions the non-contracted version "am I not" is too formal, and is avoided due to a pragmatic or stylistic pressure. In this case, the speakers fix the problem by using the next best form "aren't" which can be analyzed as underspecified for person and number, and so is the least marked "default" form in the paradigm. For a more 
precise analysis along these lines in a morphosyntactic version of OT see Bresnan (2001).

A legitimate worry is that allowing morpho-syntax to freely interact with phonology creates a theory that is too powerful. This worry perhaps could be addressed by assuming that morphological faithfulness constraints start out really high in the learning process, higher than the phonological constraints. I leave the exploration of this possibility to future research. What is attractive about the model in which morphological markedness/faithfulness and phonological markedness/faithfulness interact in the process of spellout, is that a single mechanism can capture a wide variety of diverse phenomena, and no separate rules deleting or inserting features into lexical entries or syntactic representations have to be assumed.

\section{References}

Arregi, K. \& A. Nevins (2006). Obliteration vs. impoverishment in the Basque g-/z- constraint. Penn linguistics colloquium special session on distributed morphology, vol. 30, 1-14.

Artés, Eduard (2014). Valencian hypocoristics: when morphology meets phonology. Kingston, John, Claire MooreCantwell, Joe Pater \& Robert Staubs (eds.), Supplemental proceedings of Phonology 2013, LSA.

Bailyn, John \& Andrew Nevins (2008). Russian genitive plurals are impostors. Bachrach, Asaf \& Andrew Nevins (eds.), Inflectional Identity, Oxford University Press, chap. 8, 237-270.

Bonet, E. (1991). Morphology after Syntax: Pronominal Clitics in Romance. Ph.D. thesis, MIT.

Bresnan, Joan (2001). Explaining morphosyntactic competition. Baltin, Mark \& Chris Collins (eds.), Handbook of Contemporary Syntactic Theory, Blackwell, Oxford.

Brunner, J. (2010). Phonological length of number marking morphemes in the framework of typological markedness. Fuchs, S., P. Hoole, C. Mooshammer \& M. Zygis (eds.), Between the Regular and the Particular in Speech and Language, Peter Lang, Berlin, 5-28.

Calabrese, Andrea (2011). Investigations on markedness, syncretism and zero exponence in morphology. Morphology 21, 283-325.

Croft, William (2003). Typology and universals. Cambridge University Press, Cambridge, 2nd edn.

Crosswhite, Katherine (1999). Intra-paradigmatic homophony avoidance in two dialects of Slavic. Gordon, Matthew K. (ed.), UCLA Working Papers in Linguistics, vol. 1 of Papers in Phonology 2.

Gouskova, Maria (2012). Unexceptional segments. Natural Language and Linguistic Theory 30:1, 79-133.

Hale, Kenneth (1973). Deep-surface canonical disparities in relation to analysis and change: An Australian example. Sebeok, Thomas (ed.), Current trends in linguistics, Mouton, The Hague, vol. 11, 401-458.

Halle, Morris \& Alec Marantz (1993). Distributed morphology and the pieces of inflection. Hale, K. \& S. J. Keyser (eds.), The View from Building 20, MIT Press, Cambridge, Mass., 111-176.

Halle, Morris \& Alec Marantz (1994). Some key features of distributed morphology. MIT Working Papers in Linguistics 21, 275-288.

Haspelmath, Martin (2006). Against markedness (and what to replace it with). Journal of Linguistics 42:1.

Ito, Junko \& Armin Mester (2004). Morphological contrast and merger: ranuki in Japanese. Journal of Japanese Linguistics 20, 1-18.

Jakobson, Roman (1957). The relationship between genitive and plural in the declension of Russian nouns. ScandoSlavica 3:1, 181-186.

Jones, Daniel \& Dennis Ward (1969). The phonetics of Russian. Cambridge University Press, Cambridge.

Kager, René (1999). Optimality Theory. Cambridge University Press, Cambridge.

Kenstowicz, Michael (2005). Paradigmatic uniformity and contrast. Downing, Laura, T. A. Hall \& Renate Raffelsiefen (eds.), Paradigms in phonological theory, Oxford University Press, Oxford.

Kim, Yuni (2010). Phonological and morphological conditions on affix order in Huave. Morphology 20, $133-163$.

Kochetov, Aleksej (2002). Production, Perception and Emergent Phonotactic Patterns. Routledge, New York.

López García, Ángel (1995). Gramática Muisca. LINCOM Europa, München, Newcastle.

Lubowicz, Anna (2007). Paradigmatic contrast in Polish. Journal of Slavic linguistics 15:2, 229-262.

Manzini, M.R. \& L. Savoia (2005). I dialetti Italiani e Romanci. Morfosintassi Generativa, Edizioni dell'Orso, Alessandria.

Noyer, Rolf (1998). Impoverishment theory and morphosyntactic markedness. Brentari, D. K. \& P. M. Farrell (eds.), Morphology and its relation to phonology and syntax, CSLI, Stanford, 264-285.

Pertsova, Katya (2004). Distribution of genitive plural allomorhs in the Russian lexicon and in the internal grammar of native speakers. MA thesis, UCLA.

Pertsova, Katya (2014). Phonological and morphological constraints interact: a case of Russian gen-pl allomorphy. Ms. under review.

Rebrus, Péter \& Miklós Törkenczy (2005). Uniformity and contrast in the Hungarian verbal paradigm. Downing, Laura, T. A. Hall \& Renate Raffelsiefen (eds.), Paradigms in phonological theory, Oxford University Press, Oxford.

Silverstein, Michael (1976). Hierarchy of features and ergativity. Dixon, R.M.W. (ed.), Grammatical categories in Australian languages, Humanities Press, New Jersey, 112-171. 
Stump, Gregory T. (2001). Inflectional Morphology: A Theory of Paradigm Structure. Cambridge University Press, Cambridge.

Teeple, David (2008). Lexical selection and strong parallelism. ROA archive 000992 .

Walker, Rachel \& Bella Feng (2004). A ternary model of morphology-phonology correspondence. Proceedings of WCCFL 23, vol. 23, 773-786.

Wolf, Matthew A. (2008). Optimal interleaving: serial phonology-morphology interaction in a constraint-based model. Ph.D. thesis, University of Massachusetts Amherst.

Yearley, Jennifer (1995). Jer vowels in Russian. Beckman, J. L., L. W. Dickey \& S. Urbanczyk (eds.), Papers in Optimality Theory, GLSA, Amherst, MA, 533-571.

Zwicky, Arnold M. (1978). On markedness in morphology. Die Sprache 24:2, 22-37. 